\title{
Arterial Injury, CTCAE
}

National Cancer Institute

\section{Source}

National Cancer Institute. Arterial Injury, CT CAE. NCI Thesaurus. Code C143296.

A finding of damage to an artery. 